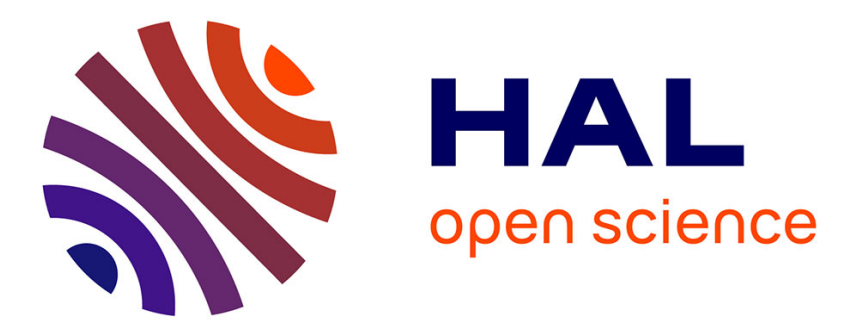

\title{
Solar radiation prediction for a winter day using ARMA model
}

\author{
Ines Sansa, Zina Boussaada, Mourad Mazigh, Najiba Mrabet Bellaaj
}

\section{To cite this version:}

Ines Sansa, Zina Boussaada, Mourad Mazigh, Najiba Mrabet Bellaaj. Solar radiation prediction for a winter day using ARMA model. 2020 6th IEEE International Energy Conference (ENERGYCon), Sep 2020, Gammarth (virtual), Tunisia. pp.326-330, 10.1109/ENERGYCon48941.2020.9236541 . hal03036381

\section{HAL Id: hal-03036381 https://hal.science/hal-03036381}

Submitted on 18 Jan 2021

HAL is a multi-disciplinary open access archive for the deposit and dissemination of scientific research documents, whether they are published or not. The documents may come from teaching and research institutions in France or abroad, or from public or private research centers.
L'archive ouverte pluridisciplinaire HAL, est destinée au dépôt et à la diffusion de documents scientifiques de niveau recherche, publiés ou non, émanant des établissements d'enseignement et de recherche français ou étrangers, des laboratoires publics ou privés. 


\title{
Solar radiation prediction for a winter day using ARMA model
}

\author{
Ines SANSA ${ }^{(1)}$, Zina BOUSSAADA ${ }^{(2)}$, Mourad MAZIGH ${ }^{(3)}$, Najiba MRABET BELLAAJ $^{(1,3)}$ \\ (1) Université de Tunis El Manar, Ecole Nationale d'Ingénieurs de Tunis, LR11ES15, Laboratoire des Systèmes Electriques, 1002, Tunis, \\ Tunisie \\ (2) Univ. Bordeaux, ESTIA Institute of Technology, F-64210, Bidart, France \\ (3) Université de Tunis El Manar, Institut Supérieur d'Informatique 2080, Ariana, Tunisie
}

ines.sansa@yahoo.com; z.boussaada@estia.fr; mazighm@hotmail.com;najiba.bellaaj@isi.rnu.tn

\begin{abstract}
Solar radiation prediction has a great importance for many applications such as PV power forecasting and solar water heaters. The need of solar radiation prediction increase over time and certainly the accurate prediction can greatly improve the performance of these applications. In this paper a prediction of solar radiation for a winter day using ARMA model is performed. The performance of this model to predict the solar radiation has been validated for a real database. Simulations results show that the effectiveness of ARMA model is proven to predict especially the small variation of solar radiation.
\end{abstract}

Keywords - Solar radiation, ARMA, Prediction

\section{INTRODUCTION}

The prediction of the solar radiation represents a difficult task since it depends to different climatic factors such as temperature, atmosphere incidence, cloud cover, wind speed, humidity, etc. The accurate prediction is more related to the suitable choice of the prediction technique. In the literature, solar radiation forecasting techniques are classified on two main groups. The first one models solar radiation as mathematical and differential equations, it takes into account some physical phenomena such as the interaction between the solar radiation and the atmosphere as well as the radiation absorption by ozone [1-4]. The second one, which is the most used, treats the solar radiation as time series, it interests to its static aspect. It is based on the solar radiation measurements in order to predict its future values. Different methods are presented in the literature to predict the solar radiation time series [5-6]. Naïve models such as the average and the persistence are the simplest solar radiation prediction technique. These models are based on the last observed variable [7], they are simple but not very precise. Markov chain is a stochastic process that has the Markovian property. In prediction, it is based only on the present events, in fact, a future state is modelled using a probabilistic process that depends only on present states. This technique is rarely used for the solar radiation prediction. Bayesian inference is mainly based on the conditional probability. The estimation of the probability series at a given horizon can be performed by Bayes 'theorem [8]. Similar to Markov chain, Bayesian inferences are rarely used for the solar radiation prediction. They are difficult to manipulate and require several parameters. In this paper, ARMA model is used to predict the solar radiation. This model is characterized by its ability to extract the useful statistical properties. It is among the most used models for time series predictions and its effectiveness in solar radiation prediction is well proven in some research work [9-10]. The present paper is organized as follows, a general presentation of the propagation of solar radiation in the atmosphere is made in the section 2 . Then the different solar radiation forms are modeled based on some topological and geometrical factors. In the section 3, the ARMA model process is firstly presented and explained, after that, the solar radiation will be predicted for a winter day. The different simulation results are presented and discussed in the second part of this section and a conclusion is introduced in the end of this paper.

\section{SOLAR RADIATION PRESENTATION}

\section{A. Solar radiation propagation in the atmosphere}

Into the atmosphere solar radiation can be absorbed, diffused and reflected as the following explanations:

- Solar radiation is absorbed by the gas molecules which it encounters in the atmosphere, this absorption is selective because it operates to very precise wavelength values. It is mainly due to water vapor, carbon dioxide, ozone and oxygen.

- Solar radiation can be diffused in all directions. This phenomenon is occurred in a medium which contains fine molecules and it strongly depends to these molecules size.

- Solar radiation is reflected by the earth's surface and then the soil reflects the radiation diffusely and anisotropically.

These different solar radiation interactions with the atmosphere are presented in the Fig.1. 


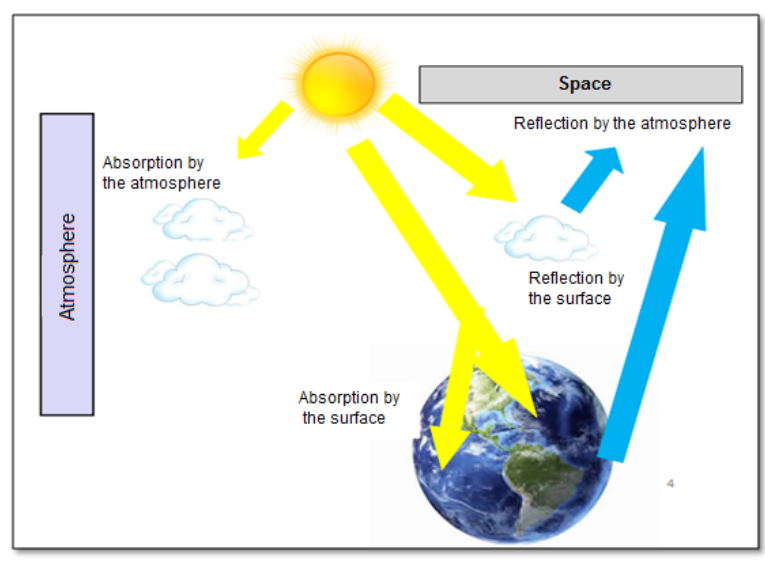

Fig.1. Solar radiation interaction with the atmosphere

\section{B. Modeling of solar radiation}

Different theories are developed to model and compute the solar radiation [1][11][12]. Therefore, in a given location and at a specific moment, the solar radiation cannot be modeled without requiring different factors such as the nature of the sky and the position of the sun relative to the earth. As mentioned previously, solar radiation has three different components, diffused, reflected and absorbed. All these radiations components are modeled by the global or total solar radiation, as presented in " 1 ".

$$
R_{t o t}=R_{\text {dir }}+R_{\text {dif }}+R_{\text {ref }}
$$

With $R_{t o t}$ is the total solar radiation, $R_{d i r}, R_{d i f}$ and $R_{\text {ref }}$ are respectively the directed, diffused and reflected solar radiation. They are expressed in the following equations,

$$
\begin{gathered}
R_{\text {dir }}=\text { Sh.Rout. } \tau^{M} \cdot \cos (i) \\
R_{\text {diff }}=\text { Rout. }\left(0.271-0.294 \cdot \tau^{M}\right) \cdot \sin (\alpha) \\
R_{\text {ref }}=\text { r.Sc. }\left(0.271+0.706 \cdot \tau^{M}\right) \cdot \sin (\alpha) \cdot \sin ^{2}\left(\frac{x}{2}\right)
\end{gathered}
$$

With $S h$ is a binary umbrage value that computed for each hour in the day. $S h$ is assigned to 0 when the solar radiation is projected to the neighbouring mountain umbrage, else it is assigned to 1. $r$ represents the reflectance of the soil which is also called the reflection factor. $S c$ is the solar constant, it is equal to $1367 \mathrm{~W} / \mathrm{m}^{2}$. Elevation angle is presented in (5) [13],

$$
\sin \alpha=\sin \varphi \cdot \sin (\delta)+\cos (\varphi) \cdot \cos (\eta)
$$

$\varphi$ represents the latitude for each PV cell, $\eta$ is the solar time, $\delta$ represents the solar declination, this parameter depends on the day of the year $j$ and it expressed as presented in (6),

$$
\delta=23.45 . \sin \left(360 \cdot \frac{284+j}{365}\right)
$$

Azimuth angle is defined as presented in (7),

$$
\cos \beta=(\sin \delta \cdot \cos \varphi-\cos \delta \cdot \sin \varphi \cdot \cos \eta) / \cos \alpha
$$

Rout represents the solar flow, and it is expressed as written in (8), it depends on the day of the year $j$ and the solar constant Sc.

$$
\text { Rout }=S c .\left(1+0.034 \cdot \cos \left(\frac{360 j}{365}\right)\right)
$$

$\tau^{\mathrm{M}}$ represents the transmissivity coefficient, it is defined as the fraction of the solar radiation incident on the atmosphere surface that reaches the soil along a vertical trajectory.

\section{PREDICTION OF SOLAR RADIATION FOR A WINTER DAY USING ARMA MODEL}

The objective of this work is to predict the solar radiation using ARMA model. This prediction is performed for a winter day. The data base solar radiation considered for the prediction is composed of solar radiation measurements related to an industrial company located in Barcelona north [14]. The time interval of these measurements is five minutes during the 2010 year as presented in the Fig. 2 .

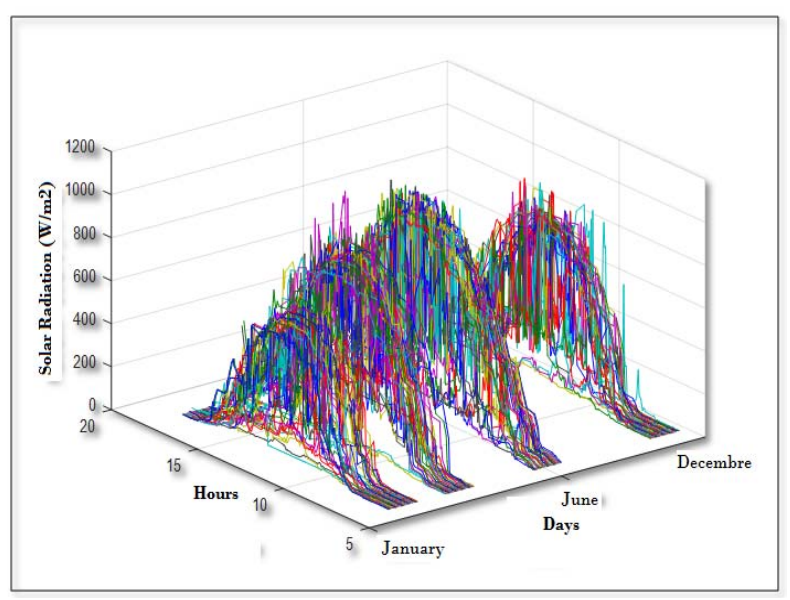

Fig.2. Annual solar radiation evolution

\section{A. ARMA model}

ARMA model is the combination of two sub-models, Auto Regressive (AR) and Moving Average (MA). It is characterized by its ability to extract useful statistical properties. AR model assumes that each point can be predicted by the sum of the $p$ previous points and a random error as written in " 9 ",

$$
x(t)=\alpha_{1} \cdot x(t-1)+\alpha_{2} \cdot x(t-2)+\cdots \alpha_{p} \cdot x(t-p)+\varepsilon_{t}
$$

$\alpha_{\mathrm{i}}$ represent the AR coefficients, they are to be estimated. $\varepsilon_{\mathrm{t}}$ is a white noise.

The MA model assumes that each point is the function of the $q$ previous errors and its own error. The equation "10" define the MA expression,

$$
x(t)=\beta_{1} \cdot e(t-1)+\beta_{2} \cdot e(t-2)+\cdots \beta_{q} \cdot e(t-q)
$$

The $\beta_{\mathrm{i}}$ values are the MA coefficients, they will be estimated as well. 
A combination of these two models forms the ARMA $(p, q)$ model, its expression is described in the equation (11),

$$
\begin{aligned}
\mathrm{x}(\mathrm{t})=\alpha_{1} \cdot \mathrm{x}(\mathrm{t}-1) & +\alpha_{2} \cdot \mathrm{x}(\mathrm{t}-2)+\cdots \alpha_{\mathrm{p}} \cdot \mathrm{x}(\mathrm{t}-\mathrm{p}) \\
+ & \beta_{1} \cdot \mathrm{e}(\mathrm{t}-1)+\beta_{2} \cdot \mathrm{e}(\mathrm{t}-2) \ldots \beta_{\mathrm{q}} \cdot \mathrm{e}(\mathrm{t}-\mathrm{q}) \\
+ & \varepsilon_{\mathrm{t}}
\end{aligned}
$$

\section{B. Simulation results}

The prediction is performed for the January 2. The choice is an example to be treated as a winter day. The solar radiation for this day is presented in the Fig.3, it is low on the morning and it is increased to achieve a maximum value equivalent to $599 \mathrm{~W} / \mathrm{m}^{2}$ in the afternoon. From $14 \mathrm{~h}$, solar radiation decreases, and it cancels towards $17 \mathrm{~h} 33$, this time corresponds to the sunset time for this day.

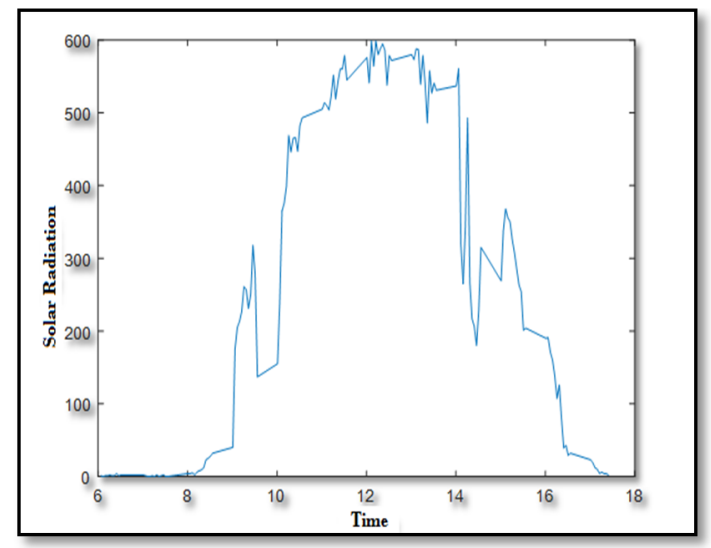

Fig.3. Solar radiation evolution in $\mathrm{w} / \mathrm{m}^{2}$ for a winter day

To study the stationarity of this series, the Dickey-Fuller test must be applied. The test results is presented in the Fig.4, it designates the presence of the unit root which improve the non stationarity of this series.

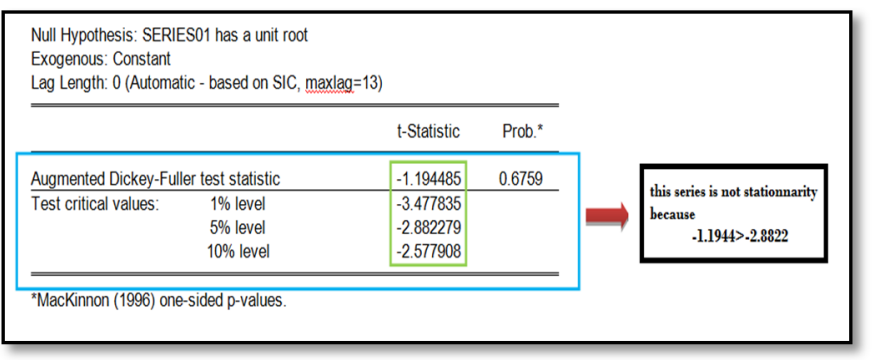

Fig.4. Dickey-Fuller test results for solar radiation series

The next step will be the differentiation of this solar radiation series in order to make it stationary. Fig. 5 presents the solar radiation evolution for a winter day after differentiation. This curve presents some intense fluctuations on the morning and other lower fluctuations just before the sunset. Solar radiation on the rest of the day is almost stable, it does not exceed $15 \%$.

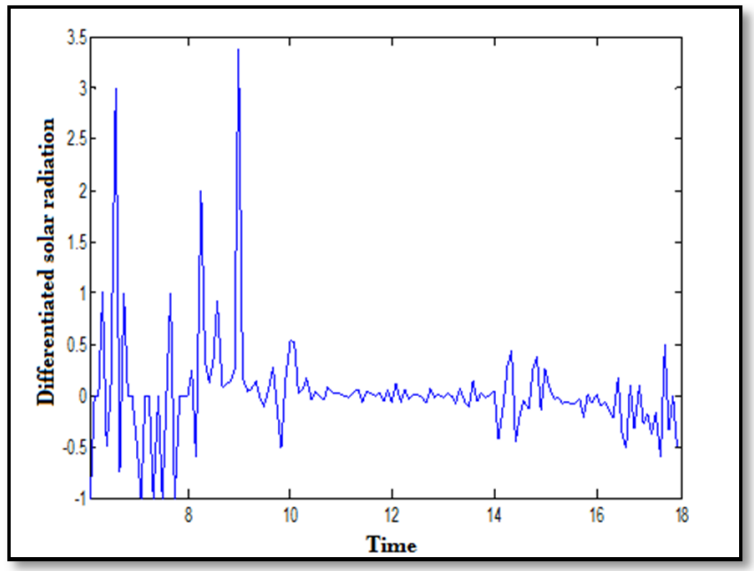

Fig.5. Relative differentiation of the solar radiation for a winter day

The Dickey-Fuller test proves the stationarity of this series as presented in the Fig.6. Thus it is possible in this step to use the ARMA model to predict this series. Next following the different Box \& Jenkins steps, the ARMA model parameters (order and coefficients) corresponding to this solar radiation time series are recapitulated in the table I.

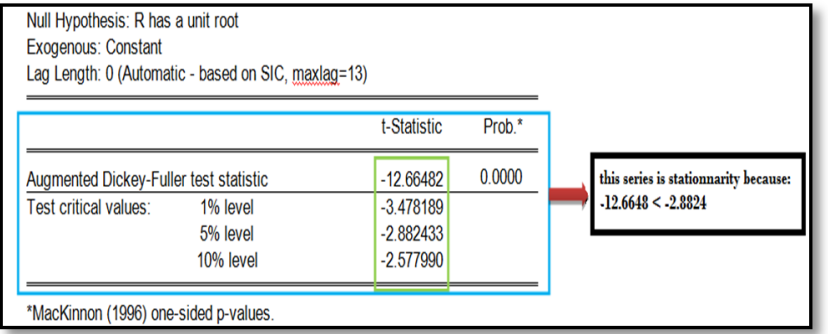

Fig.6. Dickey-Fuller test results for the relative differentiation solar radiation series

TABLE I. ORDER AND COEFFICIENTS OF ARMA MODEL FOR A WINTER DAY

\begin{tabular}{|c|c|}
\hline \multicolumn{2}{|c|}{ ARMA (p,q) } \\
\hline Order & Coefficients \\
\hline $\mathrm{p}=3$ & $\alpha_{1}=-0.5350 ; \alpha_{2}=-0.5179 ; \alpha_{3}=-0.7095$ \\
\hline $\mathrm{q}=3$ & $\beta_{1}=0.4833 ; \beta_{2}=0.5091 ; \beta_{3}=0.9569$ \\
\hline
\end{tabular}

The differentiated solar radiation and the predicted one using the $\operatorname{ARMA}(3,3)$ model are presented in the Fig.7. This presentation shows an approximation between the curves for certain time period especially when the solar radiation does not present important fluctuations. For other moments, the predicted curve diverges from the real one. This is especially observed when the solar radiation presents significant fluctuations. 


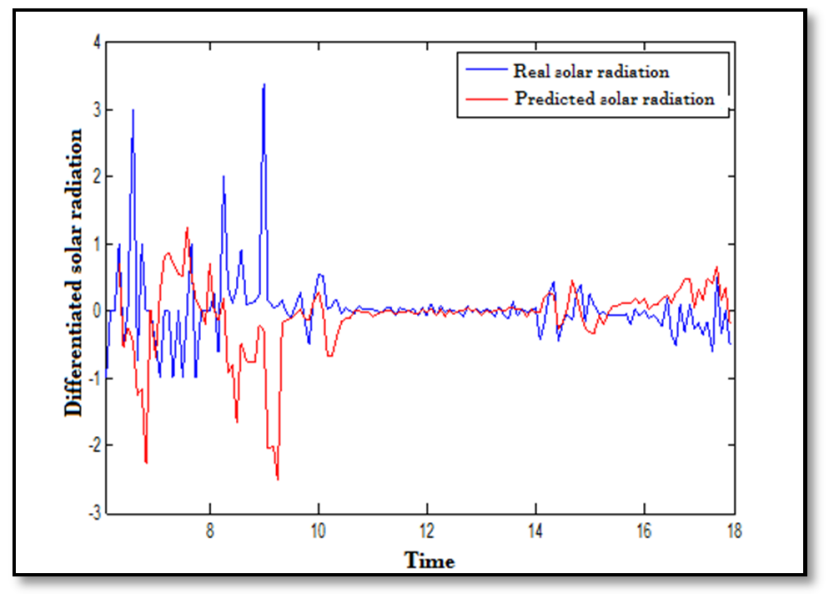

Fig.7. Solar radiation for a winter day predicted by $\operatorname{ARMA}(3,3)$

To evaluate the ARMA $(3,3)$ model performances for solar radiation prediction, error and relative error prediction are evaluated and presented in the Fig.8. Similarly, the MSE (Mean Square Error), MAE (Mean Absolute Error) and RMSE (Root Mean Square Error) are calculated as presented in table II.

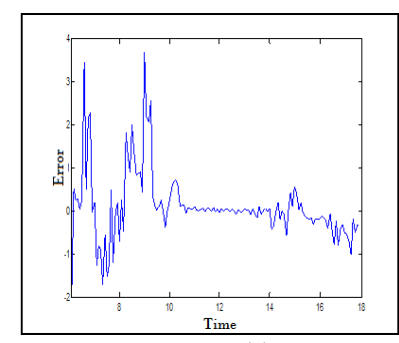

(a)

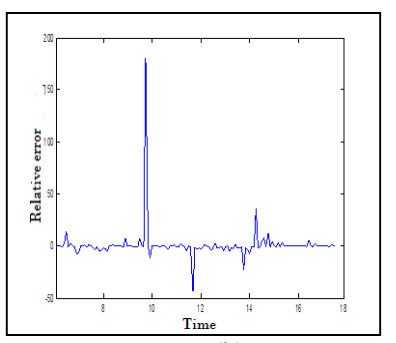

(b)
Fig.8. error (a) and relative error (b) of Solar radiation predicted by ARMA $(3,3)$

TABLE II. SOLAR RADIATION PREDICTION ERROR

\begin{tabular}{|c|c|}
\hline Error & Performances \\
\hline MSE & 0.639 \\
\hline MAE & 0.452 \\
\hline RMSE & 0.799 \\
\hline
\end{tabular}

As shown in the above table, the MAE is lower than MSE and RMSE but it is considered important. This can be explained by the wide variation of solar radiation for the winter day and especially at the day beginning. For the second time, ARMA $(3,3)$ model was used to predict the solar radiation. Simulations results for this part are presented in the Fig.9.

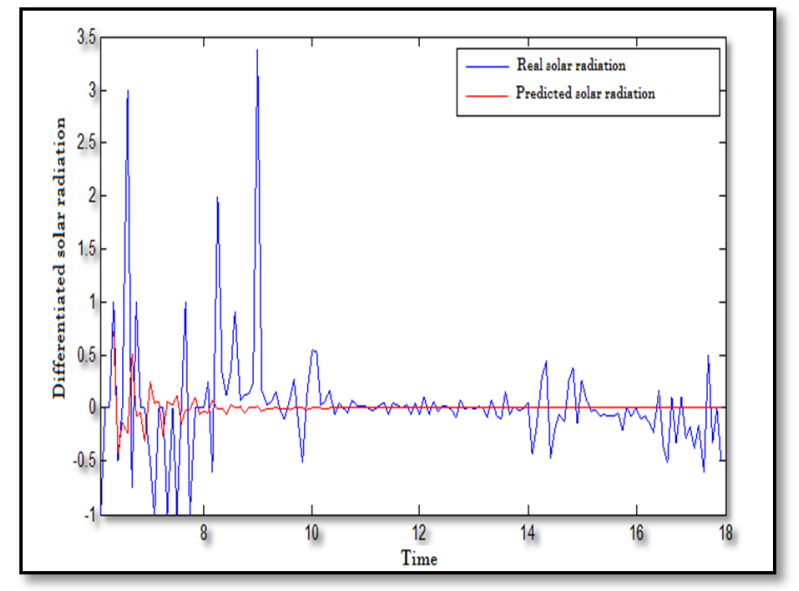

Fig.9. Solar radiation for a winter day predicted by ARMA $(3,3)$

It is observed that the ARMA $(3,3)$ model allowed to take back the first two peaks of solar radiation that not exceed $10 \%$ however it cannot predict the third solar radiation peak which is equal to $30 \%$. Then, the predicted solar radiation curve diverges from the real one until to lose all the signal. The model becomes unable to converge even for small solar radiation variation. This shows the ARMA's weakness to predict the solar radiation over one day horizon.

In the Fig.10, the prediction error and the relative one are presented. Although both do not exceed $1 \%$ in some day moments, they are fairly large in other time intervals. Table III presents the MSE, MAE, and the RMSE errors. MAE has always the smallest value but this does reflect the ARMA $(3,3)$ model performances to predict the solar radiation. It is possible to explain the weakness of this model by two main points. The first one is related to the model order which is equal to 3 . This shows that it is able to predict the first three radiations which correspond to 15 minutes. All the following solar radiation data are predicted from data that are already predicted by ARMA $(3,3)$ model which deteriorates the model predictive capacity in these time intervals. On the other hand, even in the very short term, model performances are deteriorated in the third data. This is explained by the solar radiation high peak recorded at this time.

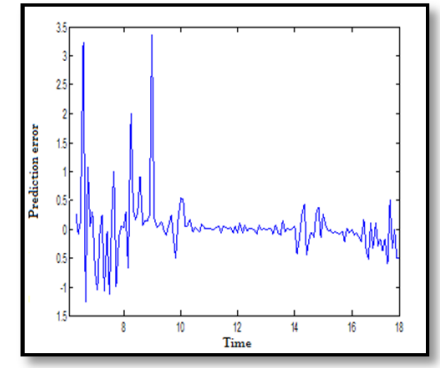

(a)

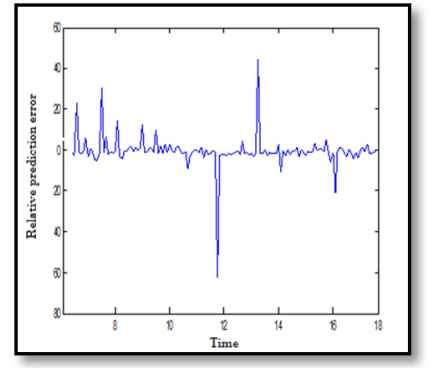

(b)
Fig.10. error (a) and relative error (b) of solar radiation prediction by ARMA $(3,3)$ for a winter day 
TABLE III. SOLAR RADIATION PREDICTION ERRORS FOR A WINTER DAY

\begin{tabular}{|c|c|}
\hline Error & Performances \\
\hline MSE & 0.2931 \\
\hline MAE & 0.2581 \\
\hline RMSE & 0.5414 \\
\hline
\end{tabular}

This research study concerned the second day of January which does not obviously represent all winter days. It is interesting so to follow the solar radiation evolution for other winter days as presented in the Fig.11. It must to be noted that the solar radiation evolutions for these different days are similar. They are always significant peaks at the beginning of the day and less intense others just before the sunset. For the rest of day, the solar radiation evolution is nearly stable, it does not present a significant variation.

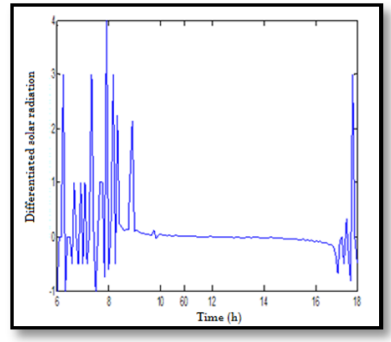

(a)

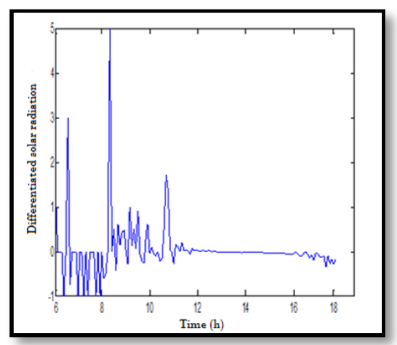

(c)

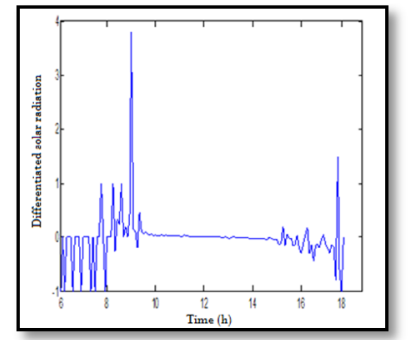

(b)

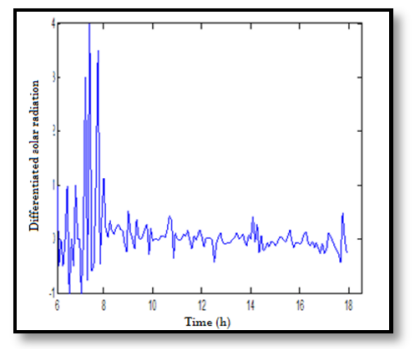

(d)
Fig.11. Differentiated solar radiation evolution for different winter days (a) $25 / 12 / 2010$ (b) $10 / 01 / 2010$ (c) $01 / 02 / 2010$ (d) $15 / 02 / 2010$

\section{CONCLUSION}

In this paper, ARMA model is used to predict the solar radiation for a winter day. Considering that ARMA model can be applied just in the stationary series, the Dickey-Fuller is used, in this work, to test the solar radiation series. First, the DickeyFuller test indicates the presence of the unit root which means the non stationarity of the solar radiation series. To make it stationary, this series is differenced and the ARMA model is applied on it. The effectiveness of ARMA model to predict the solar radiation for a winter day is proven for the small variation of solar radiation which not exceeds $10 \%$.

\section{ACKNOWLEDGMENT}

This work was supported by Tunisian Ministry of Higher Education and Scientific Research under Grant LSE-ENIT-LR $11 \mathrm{ES} 15$.

\section{REFERENCES}

[1] B.RE, RL. Hulstrom, "Evaluation and Improvement of Direct Irradiance Models,” J. Sol. Energy Eng, n¹03(3), pp 182-192, 1981.

[2] F. Kasten, "The linke turbidity factor based on improved values of the integral Rayleigh optical thickness," Solar Energy, Vol. 56(3), pp 239244, 1996.

[3] B. Molineaux, P.Ineichen, N.O'Neill, "Equivalence of Pyrheliometric and Monochromatic Aerosol Optical Depths at a Single Key Wavelength," Applied Optics, Vol.37(30), pp 7008-7018, 1998.

[4] RW. Mueller, KF. Dagestad, P. Ineichen, S. Homscheidt, "Rethinking satellite-based solar irradiance modelling: The SOLIS clear- sky module," Remote Sensing of Environment, Vol. 91(2), pp 160-174, 2004.

[5] C. Voyant, "Prediction of solar radiation time series and PV power production from artificial neural network," Phd thesis, energy specialty, November 2011.

[6] Y. Gao, M. Joo Er, "NARMAX time series model prediction: feed forward and recurrent fuzzy neural network approaches," Fuzzy Sets and Systems, Vol. 150, No. 2, pp.331-350, 2005.

[7] L.Ferrara, "Autoprojective methods of time chronological series prediction," Applied Polycopied Modeling Courses, Paris West University, February 2011.

[8] P. Lauret, E. Fock, RN. Randrianarivony, JF. Manicom-Ramsamy, "Bayesian neural network approach to short time load forecasting," Energy conversion and management, Vol 49(5), pp 1156-1166, 2008.

[9] J. Wu, C.K. Chan, "Prediction of hourly solar radiation using a novel hybrid model of ARMA and TDNN," Solar Energy 85, pp 808-817, 2011.

[10] Ji Wu, Chee Keong Chan, "Prediction of hourly solar radiation using a novel hybrid model of ARMA and TDNN," Solar Energy 85 pp 808-817.

[11] K.Liou, "An introduction to atmospheric radiation," Academic Press, 2nd Edition, vol 84, ELSEVIER STORE, April 2002.

[12] V. Badescu, "Modeling solar radiation at the earth's surface: recent advances," Springer, 2008.

[13] C. Piedallu, J.C. Gégout, "Multiscale computation of solar radiation for predictive vegetation modelling," Annals of Forest Science 64, pp 899909, 2007.

[14] Sant Joan les Fonts, Garrotxa, http://www.noel.es/ 